\title{
Utilization of community-based health planning and services compounds in the Kintampo North Municipality: a cross- sectional descriptive correlational study
}

Kenneth Wiru ${ }^{1,2^{*}}$, Akwasi Kumi-Kyereme ${ }^{2}$, Emmanuel N. Mahama ${ }^{1}$, Seeba Amenga-Etego ${ }^{1}$ and Seth Owusu-Agyei ${ }^{1}$

\begin{abstract}
Background: The Community-based Health Planning and Services (CHPS) initiative was introduced to improve coverage and utilization of basic health services for people in remote rural communities whose use of orthodox health services was hitherto limited by distance. To achieve this aim, the scheme has so far been scaled up to several communities nationwide as part of government's agenda to improve the general wellbeing of the populace. The objectives of this study were to examine the extent of patronage of CHPS compounds in the Kintampo North Municipality, factors associated with their use and challenges faced by community members regarding the use of these facilities.
\end{abstract}

Methods: We adopted a descriptive cross-sectional correlational design for this study. We collected data from 171 household heads or their representatives, selected through a multistage sampling technique. The respondents were drawn from five randomly selected communities among those with CHPS compounds and their proportions weighted based on the populations of these communities.

Results: Our analysis revealed that a high proportion (73.7\%) of the respondents patronized CHPS compounds for health care. We also found sex and income to predict the use of the facilities though income was less significant after adjusting for sex in a multivariate analysis. Females were about six times more likely than males to patronize CHPS compounds (adjusted $\mathrm{OR}=5.98,95 \% \mathrm{Cl} 2.55,14.0, P=<0.01$ ). Household heads earning between $\mathrm{GH} \zeta 200.00$ and $\mathrm{GH} \xi 300.00$ were about nine times more likely to use the facilities than those who earned below GH 100.00 (adjusted $\mathrm{OR}=8.88,95 \% \mathrm{Cl} 1.94,40.6, P=0.05)$. Our findings also showed that shortage of medicines (41.5\%), lack of money to pay for services (28.7\%) and absenteeism of Community Health Officers (CHOs) (12.3\%) were major barriers to the use of the facilities.

Conclusions: Based on the foregoing findings, there is an apparent need to ensure timely replenishment of medicines at the facilities and step up supervision of $\mathrm{CHO}$ in order to sustain patronage of the compounds.

Keywords: Community-based health planning and services, Geographic access, Rural communities, Health service utilization, Community health officers, Ghana, Kintampo North Municipality

\footnotetext{
* Correspondence: Kenneth.wiru@kintampo-hrc.org

${ }^{1}$ Kintampo Health Research Centre, Ghana Health Service, P.O Box 200, Kintampo, B/A Region, Ghana

${ }^{2}$ Department of Population and Health, University of Cape Coast, Cape Coast, Ghana
} 


\section{Background}

Globally, grave public health concerns like morbidity and health inequity result from disparities in the availability, access and utilization of health services especially in low and middle income countries. It is established that rural dwellers are more restricted in their use of formal sector health services than their urban counterparts in most of these countries [1] due to numerous socioeconomic and health system factors. Shortage of skilled personnel, medicines, inadequate personal incomes and long distance to health facilities amongst others have been reported to hamper health service utilization particularly in developing countries [2-4]. For example, Bour [4] reported an inverse relationship between distance and health service utilization in the Ashanti region of Ghana whereas Tsegay and colleagues [5] acknowledged that proximity of villages to health facilities is a strong predictor of the utilization of antenatal health services in Ethiopia. It is also documented that inadequate use of health services diminishes expectation of life and increases infant deaths in rural populations [6].

To ease the adversities associated with underutilization of health services and improve population health, most developing countries have resorted to community-based health schemes. These strategies are expected to engender and accelerate social and economic development through improved utilization of health services in view of the strong nexus between health and development. A number of studies have demonstrated the impact of community health interventions on coverage and utilization of health services worldwide. A classic case in point is the finding from the Ghana Essential Health Interventions Program (GEHIP) that was executed in the Upper East region of Ghana. The GEHIP study resulted in a $100 \%$ coverage of essential health services in the intervention districts compared to $50 \%$ coverage in the comparison districts [7]. Furthermore, a communitybased health services program in the Philippines has been reported to significantly increase the proportion of pregnant women receiving tetanus toxoid injections in an intervention community from $58 \%$ in the preintervention period to $81 \%$ at post-intervention, whilst the proportion of expectant mothers who made at least 3 prenatal visits in the intervention districts increased from $41 \%$ to $89 \%$ [8]. Moreover, Macinko and Guanais [9] documented in Brazil a 10\% increase in service coverage, which correlated with a $5 \%$ reduction in infant mortality in a community-based Family Health Program. These findings generally attest to the capacity of community oriented health initiatives to improve the utilization of health services in the beneficiary communities and general population wellbeing.

In Ghana, efforts to improve coverage and utilization of basic health services through local community mobilization date back to the colonial era [10]. However, virtually all these initiatives were short-lived due to resource and organizational constraints. Even so, there were renewed attempts to provide community-level vital health services to the populace after the declaration of the Primary Health Care (PHC) initiative in 1978. Based on evidence from the Danfa Comprehensive Rural Health and Family Planning Project and the Brong Ahafo Regional Integrated Development Project in the mid 1970s, the Government of Ghana deployed trained village health workers in rural communities to render essential health services [11].

Furthermore, government piloted the United Nations Children's Fund (UNICEF)-sponsored Bamako Initiative which was designed to optimize health services access and use in 1987. However, this scheme was deserted for reasons akin to those that caused the demise of previous health service strategies. Precisely, rapid volunteer attrition, poorly trained personnel and financial bottlenecks effectively ruined this initiative [12]. Subsequently, Community Health Nurses were trained and stationed in health centres to treat minor ailments and provide periodic community outreach services with a concentration on maternal and child health. But the rural outreach programmes of these nurses were fraught with transportation and resource difficulties thereby rendering them underutilized and ineffective.

Failure of the foregoing strategies to improve access and use of health services spurred the quest for a robust health system, which culminated in the development and implementation of the community-based health planning and services (CHPS) strategy in 2000 [13]. Modelled on the concept of PHC, CHPS is intended to enhance coverage and utilization of essential health services for populations in rural settings [13]. Under this initiative, districts are divided into sub-districts and further split into zones with service populations of between 3000 and 4500 in order to ensure efficient planning and delivery of health services. In each zone, a resident Community Health Officer provides both mobile doorstep and facility-based health services as well as collaborates with a Community Health Committee and health volunteers to plan and execute communitybased health programmes $[11,14]$. Consequently, the country's health service has been structured into a three-tier system with the community health compound being the first point of an individual's contact with the health system $[11,15]$.

Since the inception of this scheme, it has been scaled up to 3175 functional CHPS zones and 1410 functional CHPS compounds nationwide whilst efforts are being made to create more zones and make them conterminous with local electoral areas in the country to boost health service delivery [13]. 
This paper explored the extent of patronage of CHPS compounds in the Kintampo North Municipality and discussed factors and barriers associated with their use.

\section{Conceptual framework}

The conceptual framework for this study is based on Andersen and Newman's behavioural model of health service utilization. The model posits that health service use is a function of predisposing, enabling and need factors. It essentially intends to link people's personal characteristics to the use of health services [16]. Predisposing factors are crucial determinants of the likelihood of need for health care. They are demographic characteristics such as age, gender, marital status, level of education among others, which vary amongst persons. Hence, individuals with certain kinds of demographics may have different health needs or consume more health services than others with differing demographic characteristics although these features do not directly cause the need to utilize health services [16].

Enabling factors are the means available to aid access to and use of health services. They are community-level resources such as health facilities, health personnel and quality of health services available to people in their residential and occupational locations [16]. If a community has many health facilities and clients do not have to queue for long hours in order to obtain services, people may use them more frequently than in areas with fewer facilities and throngs of people competing for services. Personal enabling resources that determine access to and use of health services are income and wealth that allow individuals to pay for health services as determined by their health insurance status and government's policy on cost-sharing regarding the use of health services [16].

Need factors are the most direct causes of health service utilization [16]. They are either perceived or evaluated as the model stipulates. Perceived need entails how people view their general health and functional state as well as their experience of symptoms of disease or pain and whether they deem these conditions to be of adequate seriousness to require the use of health services [16]. Conversely, evaluated need, is the professional assessment of a person's health status and need for health care. In keeping with this model, perceived need better explains an individual's utilization behaviour since the decision to use a service is partly driven by perception of need [16]. For example, the occurrence of an illness or injury which creates discomfort or pain for an individual can lead him or her to seek professional help. Hence, the higher the severity or frequency of an illness the more likely a person is to use health services. Perceived need is therefore a significant factor to investigate in studies of health service utilization [16]. Even though the model encompasses several individual determinants, just a number of them have been included in the conceptual framework as not all such variables can be investigated within the ambit of the current analysis.

Figure 1 represents the conceptual framework adapted for studying the utilization of CHPS compounds. Individual determinants and health system factors are independent variables that influence the use of CHPS compounds (a visit to a CHPS Compound by a household head to seek care for himself/herself or for his/or her child), which is the dependent variable. It is believed that all the independent variables interact to determine initial use of health services from CHPS compounds. However, subsequent visits to a CHPS compound may be a function of health system enabling factors. This is due to the fact that clients would most likely form impressions about the nature of services provided in the compounds after their initial visit. Thus, their decision to make subsequent and repeated visits to the compounds might be determined by their perception of service quality, availability of community health officers and medicines (Fig. 1).

\section{Methods \\ Study area}

The Kintampo North Municipality is one of the twentyseven administrative districts of the Brong Ahafo Region of Ghana [17]. Geographically, it is located between
Individual Determinants

Predisposing Factors Enabling Factors Need Factors

Age Employment Perceived

Sex

Marital status

Education

Religion
Health System Factors

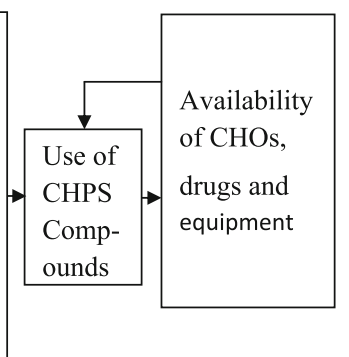

Fig. 1 Conceptual Framework for Studying the Utilization of CHPS Compounds. Source: Adapted from Andersen and Newman (2005) 
latitudes $8^{\circ} 10^{\prime}$ and $8^{\circ} 65^{\prime}$ North of the equator and Longitudes $1^{\circ} 35^{\prime}$ and $2^{\circ} 00^{\prime}$ West of the Greenwich meridian. The Kintampo Township marks the central point between the northern and southern parts of the country. The municipality is bounded to the north by the Central Gonja District and to the south by the Kintampo South District. Westwards, it is bounded by the Wenchi, Tain and Bole Districts of the Brong Ahafo and Northern Regions respectively whilst it is bounded to the East by the Pru and East Gonja Districts. It covers an area of about $5108 \mathrm{~km}^{2}$ representing $12.9 \%$ of the total land area of the region with a population of 95,480 [17].

The area is inhabited by two major indigenous ethnic groups - Bono and Mo who reside in their respective traditional communities with most of the Bono communities situated in the Eastern and SouthEastern parts of the municipality whilst the Mo predominantly occupy its Western corridor. Aside these two indigenous ethnic groups, the area has many immigrant populations of northern descent as well as a few Ewes and Dangbes who have settled along the Black Volta River where they fish for their livelihood. Its economy is largely agrarian with the major produce being yam, maize, cassava and plantain. Much of it is rural with roads that are hardly usable in the rainy season.

The Municipality has a general hospital in Kintampo from which people access health care. There are also four private health facilities, two public rural clinics, two health centres, one outreach office and twelve functional CHPS compounds across the municipality to provide for the health needs of the inhabitants (Fig. 2).

\section{Study design}

We adopted a descriptive cross-sectional correlational design for this study. This design was adopted because of its advantage of allowing for the collection of data from a sample population at one point in time and description of relationships between study variables of interest [18].

\section{Sampling procedure}

There were twelve functional CHPS communities in the Kintampo North Municipality at the time of this study. These communities had a total of 3427 active residential compounds. We employed a multistage sampling technique in selecting study participants in order to ensure representativeness. The twelve CHPS communities formed the first stage sampling units from which we randomly sampled five using Stata SE 12. We randomly selected $5 \%$ of the active residential compounds (171 compounds) from these five CHPS communities with their proportions weighted based on the number of compounds in each community. One household head or his/her representative was conveniently sampled in each of the sampled residential compounds bringing the total number of respondents to 171 . This is in keeping with the suggestion that a sample of 100 respondents is the least number required for descriptive studies whilst a sample of at least 50 is needed to establish the existence of relationships in correlational studies [19].

\section{Data collection method}

Data was collected through the administration of an interview schedule (Additional file 1) to respondents by trained field supervisors. This technique was employed because of its advantage of allowing interviewers to clarify difficult questions and probe deeper for clear-cut responses [20]. The interview schedule covered questions on background characteristics of respondents, use of CHPS compounds and barriers to their use.

\section{Data management and analysis}

We carefully checked all forms for inconsistencies before data entry and analysis. The data was entered in FoxPro version 9 and exported to Stata SE 12 for statistical analysis. We generated descriptive statistics from the data to describe background characteristics of respondents, extent of utilization of CHPS compounds and barriers to their use. Variables that were categorical in nature were summarized as proportions whilst continuous variables were expressed as means. We used univariate and multivariate logistic regression models to determine relationships between the explanatory variables of interest and use of CHPS compounds (the outcome variable). Our explanatory variables were sex, marital status, age, level of education, employment status, income level and religion.

\section{Results \\ Background characteristics of study participants}

Of all the 171 respondents interviewed, the mean age was 36.8 years with a standard deviation of 12.9. The minimum age of the respondents was 18 years whilst the maximum age was 80 years. A few (3.5\%) of the respondents were under 20 years of age. Majority $(59.1 \%)$ of them ranged between 20 and 39 years of age. Female participants were $67.3 \%$ whereas the remaining $32.7 \%$ comprised of males.

Over half of the respondents (58.5\%) were Muslims whilst Christians constituted $36.2 \%$. Practitioners of traditional religious beliefs constituted $2.3 \%$ of the respondents whereas 3\% of them belonged to other religious groupings. Majority of them (65\%) had no formal education. Respondents with primary education were $17.5 \%$ whilst those who attained middle or junior high school were $11.7 \%$. The least proportion $(5.8 \%)$ of the 


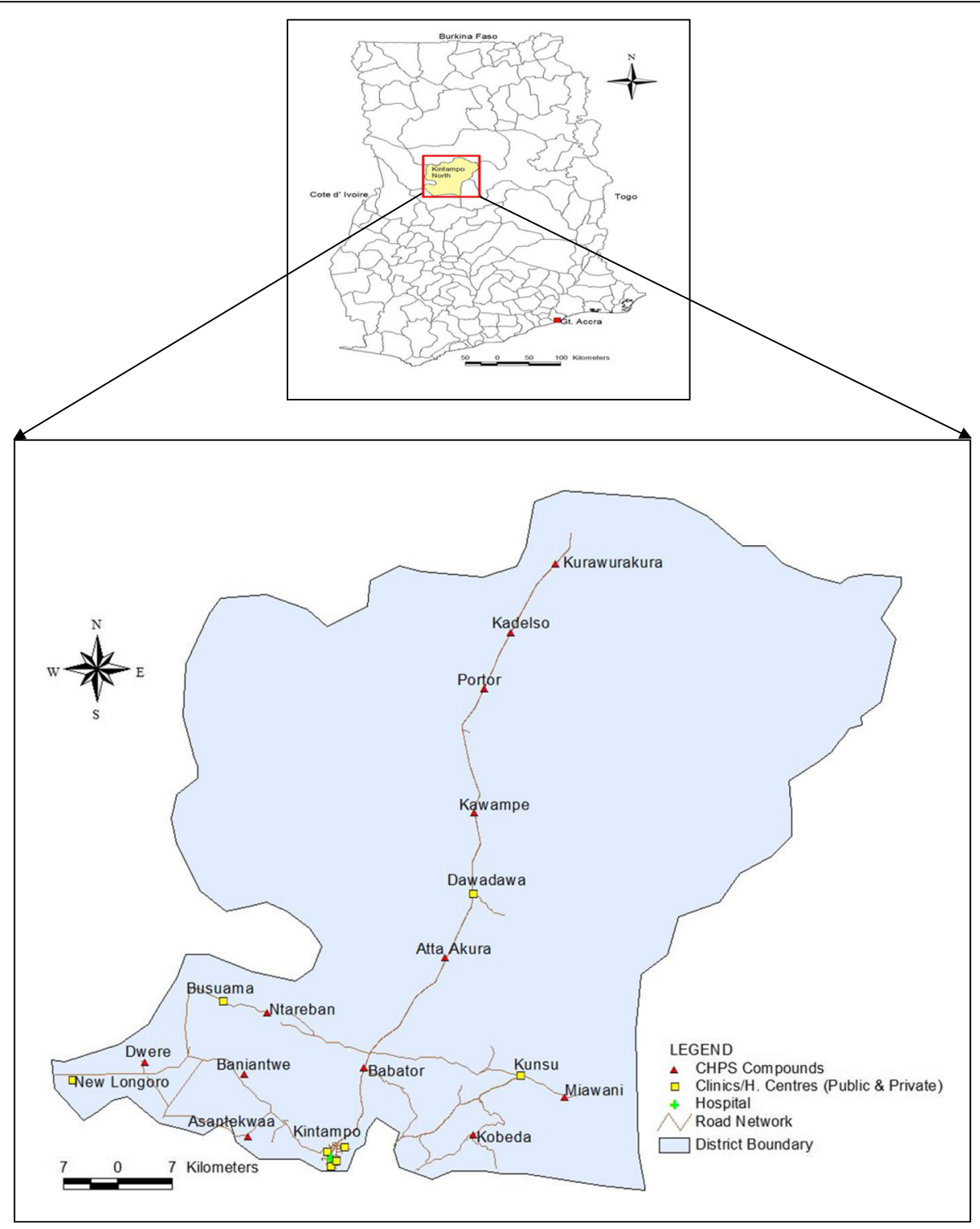

Fig. 2 Map of the Kintampo North Municipality showing Health Facilities. Source: Geographic Information Systems' Unit, Kintampo Health Research Centre (2016)

respondents attained secondary or higher education (Table 1).

More than two-thirds (69\%) of them were married. Single respondents were $21 \%$ whilst $6.5 \%$ of them were widowed. The remaining $3.5 \%$ were divorced (Table 1 ). Most (93\%) of the respondents were economically active and engaged in a number of productive ventures. Over half of the respondents (59.7\%) were engaged in farming. A number of them (26.3\%) were also engaged in diverse trading activities. Relatively fewer respondents (1.7\%) were employed in the public sector whereas $5.3 \%$ of them were engaged in other economic ventures. Regarding incomes, majority (39.2\%) of the sample earned less than one hundred Ghana cedis monthly. Those who earned between One Hundred and Two Hundred Ghana Cedis were $30.4 \%$ whilst $15.8 \%$ of them earned between Two Hundred and Three Hundred Ghana Cedis per month. Relatively $14.6 \%$ of the respondents earned a monthly income above Three Hundred Ghana cedis (Table 1).

\section{Extent of patronage of CHPS compounds}

Our findings indicate that $73.7 \%$ of household heads patronized CHPS compounds. We however observed differences in their patronage by background characteristics. As Table 2 depicts, a high proportion (83.3\%) of household heads aged less than 20 years patronized the compounds whilst a relatively low proportion $(58.3 \%)$ of 
Table 1 Background Characteristics of Respondents

\begin{tabular}{|c|c|c|c|}
\hline \multirow{2}{*}{$\begin{array}{l}\text { Characteristic } \\
\text { Age }\end{array}$} & \multirow[t]{2}{*}{ Frequency $(n=171)$} & \multicolumn{2}{|c|}{ Percentage (\%) } \\
\hline & & & \\
\hline$<20$ & 6 & 3.5 & \\
\hline $20-39$ & 101 & 59.1 & \\
\hline $40-59$ & 52 & 30.4 & \\
\hline $60+$ & 12 & 7.0 & \\
\hline Mean age $=36.8$ & $\begin{array}{l}\text { Standard } \\
\text { deviation }=12.9\end{array}$ & $\begin{array}{l}\text { Lowest } \\
\text { age }=18\end{array}$ & $\begin{array}{l}\text { Highest } \\
\text { age: } 80\end{array}$ \\
\hline \multicolumn{4}{|l|}{ Sex } \\
\hline Male & 56 & 32.7 & \\
\hline Female & 115 & 67.3 & \\
\hline \multicolumn{4}{|l|}{ Religion } \\
\hline Christianity & 62 & 36.2 & \\
\hline Islam & 100 & 58.5 & \\
\hline Traditional religion & 4 & 2.3 & \\
\hline Other & 5 & 3.0 & \\
\hline \multicolumn{4}{|l|}{ Level of education } \\
\hline None & 111 & 65.0 & \\
\hline Primary & 30 & 17.5 & \\
\hline Middle/JHS & 20 & 11.7 & \\
\hline Secondary/Higher & 10 & 5.8 & \\
\hline \multicolumn{4}{|l|}{ Marital status } \\
\hline Single & 36 & 21.0 & \\
\hline Married & 118 & 69.0 & \\
\hline Divorced & 6 & 3.5 & \\
\hline Widowed & 11 & 6.5 & \\
\hline \multicolumn{4}{|l|}{ Occupation } \\
\hline Unemployed & 12 & 7.0 & \\
\hline Farming & 102 & 59.7 & \\
\hline Trading & 45 & 26.3 & \\
\hline Government work & 3 & 1.7 & \\
\hline Other activities & 9 & 5.3 & \\
\hline \multicolumn{4}{|l|}{ Monthly income } \\
\hline Less than $\mathrm{GH} \zeta 100.00$ & 67 & 39.2 & \\
\hline GHC100.00 - GHC200.00 & 52 & 30.4 & \\
\hline GHל̨200.00 - GHל300.00 & 27 & 15.8 & \\
\hline GHC300.00 and above & 25 & 14.6 & \\
\hline
\end{tabular}

GHC $3.215=\$ 1.00$

Source: Field data, (2014)

them aged sixty years and above reportedly used the facilities. It is further observed that majority $(81.7 \%)$ of female household heads patronized CHPS compounds compared with $57.1 \%$ of their male counterparts. Besides, $77.4 \%$ of Christian household heads used the compounds compared with $75 \%$ of believers of traditional faith and $72 \%$ of Muslim household heads.
Table 2 Extent of Patronage of CHPS Compounds by Background Characteristics of Respondents

\begin{tabular}{|c|c|c|c|}
\hline \multirow[t]{2}{*}{ Characteristic } & \multicolumn{3}{|l|}{ Percentage } \\
\hline & Yes $(73.7 \%)$ & No (26.3\%) & Total (100\%) \\
\hline \multicolumn{4}{|l|}{ Age } \\
\hline$<20$ & 83.3 & 16.7 & 3.5 \\
\hline 20-39 & 74.3 & 25.7 & 59.1 \\
\hline $40-59$ & 75.0 & 25.0 & 30.4 \\
\hline $60+$ & 58.3 & 41.7 & 7.0 \\
\hline \multicolumn{4}{|l|}{ Sex } \\
\hline Male & 57.1 & 42.9 & 32.7 \\
\hline Female & 81.7 & 18.3 & 67.3 \\
\hline \multicolumn{4}{|l|}{ Religion } \\
\hline Christianity & 77.4 & 22.6 & 36.3 \\
\hline Islam & 72.0 & 28.0 & 58.5 \\
\hline Traditional religion & 75.0 & 25.0 & 2.3 \\
\hline Others & 60.0 & 40.0 & 2.9 \\
\hline \multicolumn{4}{|l|}{ Education } \\
\hline None & 72.1 & 27.9 & 64.9 \\
\hline Primary & 90.0 & 10.0 & 17.5 \\
\hline Middle/JHS & 60.0 & 40.0 & 11.7 \\
\hline Secondary/Higher & 70.0 & 30.0 & 5.9 \\
\hline \multicolumn{4}{|l|}{ Marital status } \\
\hline Single & 72.2 & 27.8 & 21.0 \\
\hline Married & 75.4 & 24.6 & 69.0 \\
\hline Divorced & 66.7 & 33.3 & 3.5 \\
\hline Widowed & 63.6 & 36.4 & 6.5 \\
\hline \multicolumn{4}{|l|}{ Employment } \\
\hline Unemployed & 66.7 & 33.3 & 7.0 \\
\hline Farming & 71.6 & 28.4 & 59.7 \\
\hline Trading & 80.0 & 20.0 & 26.3 \\
\hline Government work & 100.0 & 0.0 & 1.7 \\
\hline Others activities & 66.7 & 33.3 & 5.3 \\
\hline \multicolumn{4}{|l|}{ Income } \\
\hline$<\mathrm{GH} \not 100.00$ & 64.2 & 35.8 & 39.2 \\
\hline GHל100.00 - GHל200.00 & 7.5 & 2.5 & 3.0 \\
\hline GHC200.00 - GHל300.00 & 88.9 & 11.1 & 15.8 \\
\hline GHc300 and above & 80.0 & 20.0 & 14.6 \\
\hline
\end{tabular}

GHC $3.215=\$ 1.00$

Source: Field data, (2014)

Majority (90\%) of respondents with primary education patronized CHPS compounds whilst $72.1 \%$ of those without formal education used them. Similarly, $70 \%$ of respondents with secondary or higher education patronized CHPS compounds compared with $60 \%$ of those with middle or junior high school education (Table 2). 
Additionally, the bivariate analysis showed that a greater proportion $(75.4 \%)$ of married household heads patronized CHPS compounds. A high proportion (72.2\%) of single household heads also patronized the facilities compared with divorced and widowed household heads who reported patronage levels of $66.7 \%$ and $63.6 \%$ respectively (Table 2 ).

Close to three-quarters $(74.2 \%)$ of household heads in employment utilized CHPS compounds compared with $66.7 \%$ of their unemployed counterparts. Similarly, approximately $89 \%$ of the respondents who earned between two hundred and three hundred Ghana cedis monthly patronized the compounds. This contrasts with $75 \%$ of household heads earning between one hundred and two hundred Ghana cedis and $64.2 \%$ of those earning less than one hundred Ghana cedis monthly (Table 2).

\section{Factors associated with the utilization of CHPS compounds}

Among our explanatory variables, sex and income emerged as significant determinants of utilizing CHPS compounds. None of the other variables was significant in the univariate analysis (Table 3). The odds ratios showed that females were a little over three times more likely to use CHPS compounds than males (OR $=3.35$, 95\% CI 1.63, 6.90, $P=0.01)$. Household heads who earned between GHC 200.00 and GHC 300.00 monthly were also about four times more likely to use a CHPS compound than those who earned less than GHC 100.00 (OR $=4.46$, 95\% CI 1.18, 16.7, $P=0.02$ ).

Moreover, the association between sex and CHPS compound use became more significant after adjusting for income in the multivariate analysis. Females were about six times more likely to use a CHPS compound than males (adjusted OR $=5.98,95 \%$ CI 2.55, 14.0, $P=<0.01)$. However, income appeared less significant after adjusting for sex in the multivariate analysis (Table 3). Household heads earning between GHC 200.00 and GHC 300.00 were about nine times more likely to use the facilities than those who earned below GHC 100.00, though with a borderline $P$-value (adjusted $\mathrm{OR}=8.88$, 95\% CI 1.94, 40.6, $P=0.05$ ) (Table 3).

\section{Barriers to the use of CHPS compounds}

Shortage of medicines in CHPS compounds was reported by $41.5 \%$ of the respondents $(37.5 \%$ of males and $43.5 \%$ of females respectively) as a major barrier (see Table 4). Besides shortage of medicines, a relatively high proportion $(28.7 \%)$ of the respondents mentioned inadequate money to pay for services. However, men appeared more financially challenged than women as $37.5 \%$ of them reported their inability to use the facilities due to lack of income whereas $24.4 \%$ of their female counterparts cited same reason for not patronizing the compounds. Furthermore, $12.3 \%$ of household heads ( $8.9 \%$ of males and $13.9 \%$ of females respectively) stated that absenteeism of Community Health Officers made it difficult for them to utilize health services (Table 4).

\section{Discussion}

Overall, our findings have shown a high patronage of CHPS compounds by community members in the study area. Although the current study did not measure the relationship between distance and patronage of the compounds, the evidence garnered suggests that the high patronage of the facilities stems from their proximity to community members. This is due to the fact that most people in CHPS beneficiary communities do not have to travel longer distances to access health care as distance has been documented in previous studies to negatively affect health service use $[3,4]$. The high patronage of CHPS compounds also suggests that most persons perhaps lacked a convenient source of care prior to the introduction of the CHPS strategy. This implies that access to locally available basic health services may reduce the use of high order and distant facilities, which inhabitants of rural and low-income areas may find difficult to access.

The observed age variations in patronage of the compounds, albeit less striking suggests a downward trend in their use with progression in age. This seems to contradict the notion that frailty and need for health care become grave as people age and thus trigger increased consumption of health services among the aged. However, the trend observed in this study could either result from a lack of enabling resources for the aged to use health services rendered in the compounds (Fig. 1) or from the inclusion of many young women of reproductive age in the study, who most likely sought care for their children and also used antenatal and postnatal services. Provided that the former scenario holds true, our result contrasts findings of previous research that suggest a positive association between age and health service utilization [21] whereas it confirms the finding that proximity of villages to health facilities strongly encourages the use of antenatal services if the latter is true [5]. We also observed religious variations in patronage of the compounds though an association was not established between religious affiliation and use of the facilities. This notwithstanding, Christians were found to patronize the compounds most; thereby confirming an earlier finding that Ghanaian Christians utilize more modern health services than their Muslim counterparts [22].

Furthermore, our findings underscore the positive predisposing effect of sex on health service utilization [16]. The finding that more women patronized CHPS 
Table 3 Univariate and Multivariate Logistic Regression Analyses of Factors Influencing the Use of CHPS Compounds

\begin{tabular}{|c|c|c|c|c|c|c|c|}
\hline \multirow[b]{2}{*}{ Characteristics } & \multicolumn{4}{|c|}{ Univariate logistic regression } & \multicolumn{3}{|c|}{ Multivariate logistic regression } \\
\hline & n (\%) & $\mathrm{OR}^{\rho}$ & $95 \% \mathrm{Cl}$ & $\mathrm{P}^{a}$ & $\overline{\mathrm{OR}^{\varphi}}$ & $95 \% \mathrm{Cl}$ & $p^{\beta}$ \\
\hline \multicolumn{8}{|l|}{ Age } \\
\hline$<20$ & $5(83.3)$ & 1 & & & & & \\
\hline $20-39$ & $75(74.3)$ & 0.84 & $(0.15,4.38)$ & 0.83 & - & - & - \\
\hline $40-59$ & $39(75)$ & 0.90 & $(0.15,5.18)$ & 0.91 & - & - & - \\
\hline $60+$ & $7(58.3)$ & 0.28 & $(0.03,2.18)$ & 0.22 & - & - & - \\
\hline \multicolumn{8}{|l|}{ Gender } \\
\hline Male & $32(57)$ & 1 & & & 1 & & \\
\hline Female & $94(81.7)$ & 3.35 & $(1.63,6.90)$ & 0.01 & 5.98 & $(2.55,14.0)$ & $<0.01$ \\
\hline \multicolumn{8}{|l|}{ Religion } \\
\hline Christianity & $48(77.4)$ & 1 & & & & & \\
\hline Islamic & $72(72)$ & 0.75 & $(0.35,1.58)$ & 0.45 & - & - & - \\
\hline Traditional & $3(75)$ & 0.87 & $(0.08,9.43)$ & 0.91 & - & - & - \\
\hline Other religious beliefs & $3(60)$ & 0.43 & $(0.06,2.87)$ & 0.38 & - & - & - \\
\hline \multicolumn{8}{|l|}{ Educational level } \\
\hline None & $80(72)$ & 1 & & & & & \\
\hline Primary & $27(90)$ & 3.48 & $(0.97,12.41)$ & 0.05 & - & - & - \\
\hline Middle/JHS & $12(60)$ & 0.58 & $(0.21,1.57)$ & 0.28 & - & - & - \\
\hline Secondary/Higher & $7(70)$ & 0.90 & $(0.21,3.76)$ & 0.89 & - & - & - \\
\hline \multicolumn{8}{|l|}{ Marital status } \\
\hline Single & $26(72.2)$ & 1 & & & & & \\
\hline Married & 89 (75.4) & 1.18 & $(0.50,2.75)$ & 0.70 & - & - & - \\
\hline Divorced & $4(66.7)$ & 0.76 & $(0.11,5.00)$ & 0.78 & - & - & - \\
\hline Widowed & $7(63.4)$ & 0.67 & $(0.15,2.84)$ & 0.58 & - & - & - \\
\hline \multicolumn{8}{|l|}{ Employment } \\
\hline Unemployed & $8(66.7)$ & 1 & & & & & \\
\hline Farming & $73(71.6)$ & 1.25 & $(0.34,4.56)$ & 0.72 & - & - & - \\
\hline Trading & $36(80)$ & 2 & $(0.48,8.17)$ & 0.33 & - & - & - \\
\hline Government work & $3(100)$ & 1 & - & - & - & - & - \\
\hline Other activities & $6(66.7)$ & 1 & $(0.15,6.28)$ & 1.00 & - & - & - \\
\hline \multicolumn{8}{|l|}{ Monthly income level } \\
\hline$<\mathrm{GH} \not 100.00$ & $43(64)$ & 1 & & & 1 & & \\
\hline GHC100.00-200.00 & $39(75)$ & 1.67 & $(0.74,3.78)$ & 0.21 & 2.16 & $(0.88,5.27)$ & 0.08 \\
\hline GHC200.00-300.00 & $24(88.9)$ & 4.46 & $(1.18,16.7)$ & 0.02 & 8.88 & $(1.94,40.6)$ & 0.05 \\
\hline GHל300 and above & $20(80)$ & 2.23 & $(0.73,6.77)$ & 0.15 & 5.41 & $(1.62,18.0)$ & 0.06 \\
\hline
\end{tabular}

GHC $3.215=\$ 1.00$

Source: Field data, (2014)

$\mathrm{OR}^{\mathrm{p}}$ : Unadjusted odds ratio $\mathrm{Cl}$ : Confidence interval $\mathrm{P}^{\alpha}$ : $P$-value

$\mathrm{OR}^{\varphi}$ : Adjusted odds ratio $\mathrm{P}^{\beta}$ : Adjusted $\mathrm{P}$-value

compounds and were more likely to use them than men could be due to the fact that women have higher morbidity and use more gynaecological and obstetric services particularly in their child bearing ages [23]. The availability of maternal and child health services in CHPS compounds therefore explains the high female patronage. Conversely, the relatively low level of patronage among men possibly arises from the lack of special health services targeting men's health in these compounds. Consequently, our findings are consistent with findings of other studies that showed a higher patronage of health services for women than men [24, 25].

Additionally, our bivariate analysis indicates that patronage of CHPS compounds increases with educational 
Table 4 Barriers to the Use of CHPS Compounds

\begin{tabular}{llll}
\hline Barrier & Male & Female & Total \\
& $\mathrm{n}(56) \%(32.7)$ & $\mathrm{n}(115) \%(67.3)$ & $\mathrm{n}(171) \%(100)$ \\
\hline Lack of money & 37.5 & 24.4 & 28.7 \\
Shortage of medicines & 37.5 & 43.5 & 41.5 \\
Bad attitude of CHO & 0 & 6.1 & 4 \\
CHO not available & 8.9 & 13.9 & 12.3 \\
Long waiting times & 1.8 & 4.3 & 3.5 \\
Don't know & 14.3 & 7.8 & 10 \\
\hline
\end{tabular}

Source: Field data, (2014)

attainment. This is probably because educated persons have better knowledge of health risks, benefits and places where health services can be obtained thereby making them more inclined to use services. Lack of knowledge about treatments obtainable from health facilities due to deficient education could therefore prevent uneducated persons from using them and worsen their disease burden. This finding compares with findings of previous research in Ghana and Senegal that showed that education positively impinges on the use of health services $[22,26]$. Also, our results indicate that patronage of CHPS compounds is to some extent influenced by marital status (Fig. 1). The higher patronage of the facilities among married persons is perhaps due to the economic support that individuals in marriage unions benefit from each other. However, our finding contrasts the result of Prior and Hayes [27] that suggests that married persons use health facilities less than unmarried persons.

Analysis of the extent of patronage of the facilities by employment status showed a higher rate of patronage among employed participants than the unemployed. This finding implies that employed persons are better able to pay for health services from CHPS compounds due to the incomes earned from their jobs. Consequently, our findings validate the enabling role of employment on health service utilization reported in other studies [28, 29]. However, the role of employment in utilizing CHPS compounds becomes more evident from a close examination of the rates of patronage by type of employment of household heads. The finding that all (100\%) household heads in public sector employment and four-fifths of traders patronized CHPS compounds apparently results from the fact that their jobs provide them with income on a regular basis and so they are able to afford health services from the compounds any time they have need for care. Conversely, the relatively low level of patronage of the facilities by farmers might stem from their irregular incomes as they might be unable to afford the cost of services each time the need for care arises considering the seasonal nature of their trade.
We have effectively shown that income has an enabling effect on the patronage of CHPS compounds in the study area. Our findings imply that use of CHPS compounds increases with rising incomes. Even so, we observed that a number of household heads in the highest income category (GH\$300.00 and above) probably used health services from other facilities as they could afford the cost of transport to distant high order facilities. This is because their patronage of the compounds was about 9\% lower than the level of patronage for household heads in the Two Hundred to Three Hundred Ghana Cedis income bracket. Our finding is therefore consistent with the findings of Jatrana and Crampton [30] and Blackwell and colleagues [31] which illustrate statistically significant relationships between gender, income and health service utilization.

Ultimately, the study revealed that shortage of medicines, inadequate income and absenteeism of Community Health Officers in CHPS compounds are major impediments to the use of the facilities. These findings generally parallel those of prior studies in utilization literature and the real challenges that led to the demise of similar public health initiatives in the past. Classic examples of such programs are village health posts under the Primary Health Care initiative in Ghana and Community Health Clinics in Bangladesh [11, 32]. Our finding that absenteeism of $\mathrm{CHOs}$ impeded the use of the compounds is due to the fact that some of them do not reside in the CHPS compounds as expected.

Nevertheless, the findings emphasize the significance of health system and personal enabling resources to the use of health services (Fig. 1). Moreover, our finding that more men were financially restricted from using the compounds contrasts findings from a Chinese study that suggest that men utilize more health services and spend more on health care than women as they are financially better off [33]. Indeed, men may have the resources to pay for health care but feel more reluctant than women to seek care even if there is need for care due to cultural reasons.

\section{Limitations}

Considering time and financial inadequacies, it was not feasible to use a more representative sample of the population than was used in this study as larger numbers of respondents would have been required to be interviewed. Thus, this may reduce the reliability of our findings since the results might not have enough power to be generalised to the studied population. A larger study will be desirable to confirm some of the results in this study.

Additionally, our study was mainly based on selfreported information on utilization of CHPS compounds which may be difficult to validate. In view of the 
disjointed nature of health records obtained from the facilities, we could not extract data on patronage to complement that which was elicited from the field survey. The inclusion of quality data from these records in the analysis could have therefore provided a clear-cut picture on the extent to which the compounds were patronized.

\section{Conclusions}

Our study shows that CHPS compounds are highly patronized in the study area. Hence, they are achieving the main purpose for which the CHPS initiative was designed and implemented. Predisposing and enabling factors (sex and income) are significant determinants of the use of these compounds, though sex is a better predictor of utilization than income. Shortage of drugs, absenteeism of Community Health Officers and financial difficulties of community members are the main challenges which must be adequately addressed in order to sustain and/or improve patronage of the facilities.

\section{Additional file}

Additional file 1: Interview schedule for data collection on the utilization of Community-based Health Planning and Services (CHPS) Compounds (A list of questions asked to study participants). (DOCX $37 \mathrm{~kb}$ )

\section{Abbreviations}

CHO: Community Health Officer; CHPS: Community-based Health Planning and Services; GEHIP: Ghana Essential Health Interventions Program; PHC: Primary Health Care; UNICEF: United Nations Children's Fund

\section{Acknowledgements}

We are unreservedly grateful to the Director, management and staff of the Kintampo Health Research Centre, for supporting the lead author (Kenneth Wiru) in diverse ways throughout this study. Our gratitude also extends to all study participants for consenting to provide us with the requisite information for this study.

\section{Funding}

Not applicable.

\section{Availability of data and materials}

The datasets used and/or analysed during the current study are available from the corresponding author on reasonable request.

\section{Authors' contributions}

KW conceived, designed and executed the study. He also interpreted the findings and prepared the manuscript. AKK and SOA supervised and contributed to the design of the study. SA contributed to the development of the study instruments and supervised data entry whilst ENM analysed the data and helped interpret the findings. AKK, SOA, SA and ENM critically reviewed and edited the manuscript. All authors read and approved the final manuscript.

\section{Ethics approval and consent to participate}

Ethical approval was obtained from the Kintampo Health Research Centre's Institutional Ethics Committee for this study. Apart from following strict ethical procedures at every stage of the study to ensure data confidentiality and anonymity of the study participants, we duly explained the purpose of the study to all participants before verbally obtaining their consent to freely participate.
Consent for publication

Not applicable.

\section{Competing interests}

The authors declare that they have no competing interests.

\section{Publisher's Note}

Springer Nature remains neutral with regard to jurisdictional claims in published maps and institutional affiliations.

Received: 5 January 2017 Accepted: 14 September 2017 Published online: 26 September 2017

\section{References}

1. Strasser R. Rural health around the world: challenges and solutions. Fam Pract. 2003;20(4):457-63. doi:10.1093/fampra/cmg422.

2. Uchendu OC, llesanmi OS, Olumide AE. Factors influencing the choice of health care providing facility among workers in a local government secretariat in South-western Nigeria. Ann Ib Postgrad Med. 2013;11(2):87-95.

3. Bour D. Accessibility and utilisation of health services in Ghana. Netherlands Institute for Health Services Research (NIVEL). 2004;ISBN 90-6905-674-7. https://www.nivel.nl/nl/. Accessed 15 July 2014.

4. Noor AM, Zurovac D, Hay SI, Ochola SA, Snow RW. Defining equity in physical access to clinical services using geographical information systems as part of malaria planning and monitoring in Kenya. Trop Med Int Health. 2003:8(10):917-26. doi:10.1046/j.1365-3156.2003.01112.x.

5. Tsegay Y, Gebrehiwot T, Goicolea I, Edin K, Lemma H, Sebastian SM. Determinants of antenatal and delivery care utilization in Tigray region, Ethiopia: A cross-sectional study. Int J Equity Health. 2013;12:30.

6. Ajala OA, Sanni L, Adeyinka SA. Accessibility to health care facilities: a panacea for sustainable rural development in Osun state, south-western Nigeria. J Hum Ecol. 2005;18(2):121-8.

7. Awoonor-Williams JK, Phillips JF, Bawah AA. Catalyzing the scale-up of community-based primary healthcare in a rural impoverished region of northern Ghana. Int J Health Plann Mgmt. 2016;31:e273-89. doi:10.1002/ hpm.2304.

8. Catholic Relief Services (CRS), Philippines. Community-Based Health Program in Targeted Areas of Development: Final Evaluation Report. 2003. Available from: https://www.norad.no/en/front/toolspublications/.

9. Macinko J, Guanais FC. Evaluation of the impact of the family health program on infant mortality in Brazil, 1990-2002. J Epidemiol Community Health. 2006;60(1):13-9. doi:10.1136/jech.2005.038323.

10. Arhinful D. The solidarity of self-interest: Social and cultural feasibility of rural health insurance in Ghana. Amsterdam, Leiden: the institutional repository of the University of Amsterdam; 2003. Available from: https:// dare.uva.nl/

11. Nyonator FK, Awoonor-Williams JK, Phillips FJ, Jones TC, Miller RA. The Ghana community-based health planning and services initiative for scaling up service delivery innovation. Health Policy Plan. 2005;20(1):25-34.

12. Adjei $\mathrm{S}$, Senah $\mathrm{K}$, Cofie P. Study on the implications of community health workers' distributing drugs in Ghana. Health Research Unit: Ghana Ministry of Health; 1995.

13. Ministry of Health $(\mathrm{MOH})$ National Community-based Health Planning and Services Policy document. Ghana, Accra. 2016. Available from: http://www. moh.gov.gh/

14. Binka F, Aikins M, Sackey SO, Aryeetey R, Dzodzomenyo M, Esena R, et al. School of Public Health, University of Ghana, Legon, Accra; 2009 In-depth review of the community-based health planning services (CHPS) program. A report of the annual health sector review. Available from: www.moh.gov. gh/wp-content/uploads/../CHPS-Review-Report-FINAL-180509.pdf.

15. Ministry of Health $(\mathrm{MOH})$. Holistic Assessment of the Health Sector Programme of Work. Ghana, Accra. 2012. Available from: www.statsghana. gov.gh/nada/index.php/catalog/70/download/270.

16. Andersen R, Newman JF. Societal and individual determinants of medical care utilization in the United States. The Milbank Quarterly. 2005;83(4):1-28.

17. Ghana Statistical Service (GSS). 2010 Population and Housing Census (PHC): District Analytical Report. Kintampo North District; 2014. Available from: http://www.statsghana.gov.gh/docfiles/2010_District_Report/ Brong\%20Ahafo/Kintampo\%20North.pdf.

18. Levin KA. Evidence-Based Dentistry. 2006;7:24-25. doi:10.1038/sj.ebd 6400375. 
19. Fraenkel JR, Wallen NE, Hyun $\mathrm{HH}$. How to design and evaluate research in education. 8th ed. Mc Graw Hill: New York, NY; 2012.

20. Babbie E. The practice of social research. 12th ed. Belmont, CA: Wadsworth; 2010.

21. Vegda K, Nie JX, Wang L, Tracy CS, Moineddin R, Upshur REG. Trends in health services utilization, medication use, and health conditions among older adults: a 2-year retrospective chart review in a primary care practice. BMC Health Serv Res. 2009;9:217.

22. Saeed Bll, Munyakazi L, Aidoo EN, Yawson AE, Nsowah-Nuamah NNN, Zhao X. Socio-economic Inequalities and Healthcare Utilization in Ghana. International Journal of Business and Social Research. 2013;3(1):54-63.

23. Gong Y, Yin X, Wang Y, Li Y, Qin G, Liu L, et al. Social Determinants of Community Health Services Utilization among the Users in China: A 4-Year Cross-Sectional Study. PLoS One. 2014;9(5):e98095.

24. Weiss WM, Vu A, Tappis H, Meyer S, Haskew C, Spiegel P. Utilization of outpatient services in refugee settlement health facilities: a comparison by age, gender, and refugee versus host national status. Confl Heal. 2011;5:19.

25. Bakeera SK, Wamala SP, Galea S, State A, Peterson S, Pariyo GW. Community perceptions and factors influencing utilization of health services in Uganda. Int J Equity Health. 2009;8:25.

26. Lépine A, Le Nestour A. Health Care Utilisation in Rural Senegal: the facts before the Extension of Health Insurance to Farmers. International Labour Office, Geneva. 2011. Research Paper Number 2: Available from: http://www. ilo.org/public/english/employment/mifacility/download/repaper2.pdf

27. Prior PM, Hayes BC. Marital status and bed occupancy in health and social care facilities in the United Kingdom. Public Health. 2001;115:401-6.

28. Driscoll AK, Bernstein AB. Health and access to care among employed and unemployed adults: United States, 2009-2010. Hyattsville, MD: National Center for Health Statistics. 2012. NCHS data brief, no 83. Available from: http://www.cdc.gov/nchs/data/databriefs/db83.htm

29. Kevany S, Murima O, Singh B, Hlubinka D, Kulich M, Morin SF, Sweat M. Socio-economic status and health care utilization in rural Zimbabwe: findings from project accept (HPTN 043). J Public Health Africa. 2012;3(1):46-51.

30. Jatrana S, Crampton P. Gender differences in general practice utilisation in New Zealand. J Prim Health Care. 2009;1(4):261-9.

31. Blackwell DL, Martinez ME, Gentleman JF, Sanmartin C, Berthelot J. Socioeconomic status and utilization of health Care Services in Canada and the United States: findings from a Binational health survey. Med Care. 2009;4(11):1136-46.

32. Normand C, Iftekar MH, Rahman, SA. Assessment of the community clinics: effects on service delivery, quality and utilization of services. Health systems development Programme, Ministry of Health and Family Welfare, Dhaka, Bangladesh. 2002. Available from: http://r4d.dfid.gov.uk/pdf/outputs/ healthsysdev_kp/bang_comm_clinics_web_version.pdf

33. Song Y, Bian Y. Gender differences in the use of health care in China: a cross-sectional analysis. Int J Equity Health. 2014;13:8.

\section{Submit your next manuscript to BioMed Central and we will help you at every step:}

- We accept pre-submission inquiries

- Our selector tool helps you to find the most relevant journal

- We provide round the clock customer support

- Convenient online submission

- Thorough peer review

- Inclusion in PubMed and all major indexing services

- Maximum visibility for your research

Submit your manuscript at www.biomedcentral.com/submit 